\title{
ETHNOGRAPHICALLY ORIENTED ASSESSMENT OF AN EMERGENT MULTIDISCIPLINARY SCIENCE ESP GROUP PROJECT MODULE
}

\author{
L. J. Ngoepe \\ Department of Languages \\ University of Limpopo Turfloop Campus \\ Sovenga, South Africa \\ e-mail: lucia.ngoepe@ul.ac.za
}

\section{ABSTRACT}

When language and content lecturers in a multidisciplinary setting assess what they teach in concert, they tend to benefit from that enriching experience but students stand to benefit more. This article describes some multidisciplinary assessment of an emergent science English for Specific Purposes (ESP) project module. The quintessentially South African module is meant to enhance the performance of English and Study Skills (ESS) ESP under-prepared science students. The project was assessed formatively in concert by students, language - as well as content lecturers. This science ESP course is integrated in a Bachelor of Science Extended Degree Programme (BSC EDP) curriculum at the University of Limpopo (UL). The researcher mainly analysed the performance of the students in the project module over a four-year period.

Key words: multidisciplinary, assessment, under-prepared, science, ESP, students, emergent, project, module

\section{INTRODUCTION}

Assessing ESP science group projects remains a challenge to language lecturers. However, if language and content lecturers can assess in concert in a bid to hone their collective strengths and debilitate their weaknesses, students stand to benefit more from such interventions. The aim in this article is to discuss multidisciplinary assessment of the University of Limpopo (UL) Bachelor of Science (BSc) Extended Degree Programme (EDP) science English for Specific Purposes (ESP) project module.

\section{ASSESSMENT}

Appropriate and effective assessment is an essential part of teaching, and when instruction and assessment work together, student achievement does improve. It has also been estimated that teachers spend as much as 50 per cent of their time in assessment-related activities (Rogier 2011, 198).

Assessment lies at the heart of educational endeavor, in that, what is assessed determines 
what is taught. This centrality of assessment is universally acknowledged (Verhoeven and Verloop 2002, 91).

The ESP project assessment is formative and multidisciplinary in nature. English and Study Skills (ESS) staff plan instruction and materials in such a way that a multidisciplinary team of BSc EDP lecturers collectively take part in providing students with access to information and formative assessment of the ESP project.

De Chazal $(2014,54)$ maintains that formative assessment refers to ongoing assessment done during a teaching programme in order to monitor students' progress and give feedback with regards to specific teaching points covered.

Formative assessment is designed primarily to support teaching and learning processes. It also helps to inform the lecturer about a student's strengths and weaknesses and should feed back into his or her planning of lectures (cf. Genesee and Upshur 1996, 153; Department of Education 1997, 29).

Salvia and Ysseldyke $(1995,5)$ state that when students are assessed, the way they perform a variety of tasks in a variety of settings or contexts, the meanings of their performances in terms of the total functioning of the individual and the likely explanations for those performances are considered. Good assessment procedures take into consideration the fact that a student's performance on any task is influenced by the demands of the task and by the factors inherent in the context in which the assessment is carried out.

The challenge within ESP assessment derives from the fact that the ESP student has a definite target, which is, adequate performance in a study or work situation. Both at the start and at the end of an ESP course the lecturer needs to know how near a student is to achieving adequate performance (Robinson 1991, 73).

It is implicit that assessment procedures need to be designed or selected with a clear understanding of need and purpose (De Chazal 2014, 295). A key feature of all performance assessments is that they require students to be active participants; students are responsible for creating and constructing their responses. This type of assessment provides lecturers with information about how a student understands and applies knowledge. Performance-based assessment requires students to demonstrate that they have mastered specific skills and competencies by performing or producing something (cf. Hibbard 1996, 5; Masters and Forster 1996, 25). Moreover, the greater the diversity in the methods of assessment, the fairer assessment is to learners (Dreyer 2000, 279).

In addition, a finding across learning surveys done is that the disadvantages associated with not speaking the language of instruction at home, is nearly always the language of the test 
(Barrett 2014, 72). This is also attributable to the majority of BSc EDP students; they do not speak the language of instruction at home and by extension, the language of the test.

Traditionally, ESS students sat for four criterion-referenced tests per annum. According to Dreyer $(2000,270)$ criterion-referenced tests are used to determine whether each student has achieved specific skills or concepts. Tests and test scores are reported and interpreted with reference to specific context used to assess a student's mastery of the curriculum.

The emergent ESP project module forges productive interaction among students, ESP lecturers and content lecturers. This module will be assessed by ESS lecturers, ESS students and BSc EDP content lecturers (see Appendix).

\section{TASKS}

The terms 'task' and 'activity' are closely related. Tasks are sometimes taken to be at the level above activities, with a single task being realized through multiple activities (De Chazal 2014, 66). The ESP project is also realized through multiple activities.

Tasks hold a central place in Second Language Acquisition (SLA) research and in language pedagogy (Ellis 2003, 1). They also allow the researcher to manipulate the interactions in which learners are involved, the kind of interactional feedback they receive, and the kind of output they produce (Mackey 2012, 22). Hence the researcher investigates multidisciplinary assessment of the science ESP project module.

According to Ellis $(2003,3)$ tasks are activities that call for primarily meaning-focused language use whereas exercises are activities that call for primarily form-focused language use. However, the overall purpose of tasks is the same as exercises; learning a language. The difference lies in the means by which this purpose is to be achieved.

Each kind of task is designed to maximize opportunities for learners to use their second language, either with another comparable or more competent learner. Many tasks can be adapted to target specific linguistic structures (Mackey 2012, 22). There seems to be a relationship between the level of cognitive processing required and the kind of structuring and restructuring of language that tasks are designed to bring about. However, one of the limitations of both SLA research and language pedagogy is that not sufficient attention has been paid to the cognitive dimension of tasks. Tasks should ideally involve learners in reasoning; making connections between pieces of information, deducing new information and evaluating information (Ellis 2003, 7).

According to Mackey $(2012,22)$ tasks can be differentiated within numerous dimensions, including, but not limited to, whether the task is open or closed, one-way or two-way, and 
whether the information exchange is required or optional. For instance, consensus tasks are another example of an open two-way task involving pairs or groups of learners who need to agree on a solution to a posed problem.

Closely related to the distinction between closed and open tasks, there are convergent and divergent tasks. In a convergent task, learners are required to find a solution that is acceptable to all participants in the group (Mackey 2012, 62). In line with this, ESS students are expected to find a solution acceptable to all group participants during execution of the project.

In line with the above, a project is an important and carefully planned piece of work which is intended to build or produce something new or to deal with a problem (Longman Dictionary 1995, 1128). The ESS project is a carefully planned piece of work intended to produce something new or solve an identified problem and the ESS students carry out a number of tasks which constitute their annual project. For example, it involves students in reasoning; making connections between pieces of information, deducing new information and evaluating information (see Appendix).

The challenge for the ESP lecturers is to incorporate into their teaching materials tasks which involve critical thinking. The lecturer should also understand the importance of student autonomy in academic contexts and employ tasks, processes and interactions that require students to work effectively in groups or independently as appropriate (De Chazal 2014, 52).

Task-based language teaching should be seen as one of many possible tools in the teacher's kit. Collectively, work on tasks and work on interaction have provided valuable types of activities that are most likely to promote second language development (Mackey 2012, 74).

Moreover, learners need rich linguistic input at the right level, motivating and ageappropriate activities, and attention to their individual needs (Davidson 2014, 6).

Tasks can be used as sources of knowledge and argument for students to use in their own work (De Chazal 2014, 80) such as the ESS projects.

\section{GROUP WORK}

Lecturers believe students learn more when they work with other students than when they work alone (McMahon 2013, 11). Thus, understanding the purpose of working in groups motivates students to participate (McMahon 2013, 10).

Students are often asked to carry out work in groups because group work involves working with other students who are on the same course as they complete a task or assignment (McMahon 2013, 8). Group work can help students develop their teamwork skills as these skills are important for working effectively (McMahon 2013, 13). Students are asked to work with 
others because of the skills and subject knowledge they gain during the group work process (McMahon 2013, 15).

There are different types of tasks and assignments students can do together. These tasks will probably involve meeting in a group outside class to spend time working together. Some group work may even last for weeks or months (McMahon 2013, 9).

When students work in groups, they sometimes have the option of choosing their own group members. Alternatively, they may be told who to work with by the lecturer. Another option is to have a random selection process (McMahon 2013, 9). ESS students are also told with whom to work (see Teaching Approach).

Since group work is designed to get the best out of the individuals that make up the group, it is essential that the group should operate effectively. A group is more likely to be effective if each student is assigned a particular role together with the responsibilities which come with that role. It is also of vital significance that each group member fully understands the role and the responsibilities (McMahon 2013, 22). Thus, matching roles and responsibilities to the appropriate group member is an important skill that requires some objective judgement (McMahon 2013, 23).

Positive interdependence links students together. Hence one cannot succeed unless all group members succeed and it enables students to reach a goal beyond individual ability and maximize their learning through the dual responsibility for both oneself and the other team members. Thus, group work fosters positive interdependence and individual accountability (Johnson, Johnson and Holubec 1998).

On the other hand, individual accountability in a group requires that every teammate be accountable for completing a particular task. Techniques to ensure individual accountability typically include testing students individually after group work, assigning each member an individual role or task, and randomly selecting certain students as team representative to present team work (Johnson, Johnson and Holubec 1998).

\section{INTERACTION}

Studies on interaction in classrooms around the world have reported positive effects for interaction-driven learning (Mackey 2012, 53). Hence the significance of interaction as one the tenets of the ESP project module approach (see Teaching Approach).

In addition, Interaction Research (IR) has been acknowledged to be authentic (Mackey 2012, 38). Authenticity concerns tasks which need to correspond to some real-world activity, which is, achieving situation authenticity such as 'Communicable Diseases' and 'Green energy' 
project themes (cf. Ellis 2003, 6).

Furthermore, one of the central tenets of the Interaction Approach (IA) revolves around the importance of feedback for interlanguage development. Along with instruction, feedback is one of the ways that focuses on form and can be achieved as it helps learners 'notice the gap' (Mackey 2012, 40).

Different forms of interactional feedback can benefit second language (L2) development (Mackey 2012, 52); different types of feedback can be provided in different contexts (Mackey 2012, 40). For example, explicit feedback, which is generally less common, occur more frequently in explicit language-focused contexts than it does elsewhere (Mackey 2012, 42).

According to Mackey $(2012,59)$, there are processes which have been shown to be beneficial for L2 development; these are opportunities to receive comprehensible input, to negotiate for meaning, to produce output and have one's attention brought to points of discrepancy between interlanguage and the target language, which need to occur in a particular setting. For example, ESS students have researched ‘The South African Mining Industry’ as a theme focusing on topics such as 'Water Usage', 'Gas Emissions', 'Electricity Consumption' and Occupational Diseases’ before, in the context of mining.

\section{ESP CONTENT}

Since ESS is an intensive one year English for Specific Purposes (ESP) course, much ESP work is based on the notion of a 'common-core' of language, and skills that belong to specific academic science disciplines (cf. Ngoepe 2007).

On the other hand, Llinares, Morton and Whittaker (2012, 38) distinguish between commonsense and uncommonsense perspectives of content in the instructional register. The commonsense view uses students' and lecturers' knowledge as well as experience of everyday life whereas the uncommonsense one uses concepts from the subject being studied to describe or explain phenomena. This distinction between every day and scientific knowledge as well as the associated language, is very useful for helping lecturers and students think about what is being focused on, in lessons. Therefore, the science ESP project module integrates both the commonsense and the uncommonsense perspectives.

In any classroom situation, access to content as well as the language features necessary to express that content need to be provided by teachers (Llinares, Morton and Whittaker 2012, 91). In the same vein, ESS and BSc EDP content lecturers provide access to language features and content respectively. Thus ESS, Biology, Chemistry, Mathematics and Physics lecturers facilitate students' access to content on a given theme (see Credit Value). 
Scientific audiences expect digestible, believable and useful scientific content (Lebrun 2010, 53). But good scientists are normally neither good writers nor presenters (Glasman-Deal 2010, v). This inadequacy places a premium on science ESP project work since it affords ESS students an opportunity to write and present the work done.

ESS teaching reflects the underlying concepts such as 'Proportionality' and 'Probability' related to science content, and it includes activities of the broad discipline such as projects on 'Global Warming' and 'Energy'. Content is offered in thematic units subsuming a number of topics for lectures (cf. Ngoepe 2007, 228).

On the presentation day, students and lecturers in BSc EDP constitute a scientific audience for the invited speaker and fellow students' group presentations. This science ESP project culmination is in a form of an address by a guest speaker who should set the tone and should have specialized in the area addressed by the current theme. For example, for a 'Global Warming' theme an Environmental Science guest speaker was sought while a Chemistry or Physics guest speaker was sought for an 'Energy' theme.

\section{ESS ESP CONTEXT}

According to Batibo (2014, 16), there are several current language policy options in Africa. These are the Inclusive Language Policy (INLP), the Partially Inclusive National Language Policy (PINLP), the Exclusive National Language Policy (ENLP), Hierarchical National Language Policy (HNLP), the Colonial National Language Policy (CNLP) and the Isolation National Language Policy (INLP). South Africa opted for the PINLP. This is a national language policy in which only a selected number of major indigenous languages are promoted and used in education, administration, judiciary, and so on.

Learning surveys have been instrumental in highlighting inequalities in learning opportunities (Barrett 2014, 72). For example, research conducted on the home- and school background of the BSc EDP (UNIFY) students showed that the home backgrounds of the majority of the students have not prepared them to succeed at university. In addition, the schools they attended were situated in poverty stricken townships or rural areas. This results in students with a fairly low ability in terms of academic literacy and language proficiency (cf. Ngoepe 2007; Zaaiman 1998). It is, therefore, imperative that the language learners' curriculum be socially relevant (Davidson 2014, 6).

Although Bloch $(2014,50)$ asserts that it is now widely accepted that there is a crisis in literacy education in South Africa, Kioko $(2014,28)$ states that education can be a great equalizer. If students from different socio-economic backgrounds are provided with equal 
opportunities for education, then the society can move towards an equalitarian status.

In an attempt to address this inequality, the UL BSc EDP was introduced. Students who did not qualify to be admitted into the Science Faculty but had shown potential to succeed, were given an opportunity to study Mathematics and the Sciences. ESS is included in the BSc EDP curriculum (Ngoepe 2012, 63).

The general outcome of ESS, which is an ESP course, is that the students' academic and general proficiency in English should improve, and they should acquire language and study skills which will enhance their performance in Mathematics and the Sciences. ESS is taught in the BSc EDP curriculum together with Biology, Chemistry, Mathematics, Physics and Computer Literacy (cf. Ngoepe 2007; Fouche 2007).

Choosing to learn a second language is often more than a purely practical decision; it implies aspiration and status (Davidson 2014, 5). However, English is used as a medium of instruction in BSc EDP and at UL. For example, it is implicit that English is taught as a language in addition to the languages spoken by the South African students. But parents regard English as a language of opportunity (cf. Davidson 2014, 5).

For students embarking on a course of study in English in an unfamiliar university setting, three kinds of shock can affect them: culture and language as well as the academic one. For example, language shock will depend on the student's level of English and can express itself in different ways, such as the amount of unknown vocabulary in the text that a student has to read (De Chazal 2014, 43). Former BSc EDP students who have successfully completed the programme, mentor new students to help them adapt to their new tertiary environment.

The concept of culture serves to describe a group's belief, values and practices while accommodating the diversities of identities and practices of its individual members (Alidou and Glanz 2014, 60).

This implies that the lecturer should develop greater knowledge and understanding of the students: their learning, values, culture as well as their language, knowledge and skills (De Chazal 2014, 52). For example, students sit for an ESS diagnostic test at the beginning of the year and attend life skills sessions run by UL psychologists once a week.

In line with the above, a project is an important and carefully planned piece of work which is intended to build or produce something new or to deal with a problem (Longman Dictionary 1995, 1128). The ESS project is a carefully planned piece of work intended to produce something new or solve an identified problem. ESS students carry out a number of tasks which constitute their annual project. For example, the ESP project involves students in reasoning; making connections between pieces of in information, deducing new information and 
evaluating information (see Appendix).

Moreover, Davidson $(2014,5)$ maintains that languages are central in giving people their identity, and in defining as well as limiting the range of people we interact with. This, therefore, makes language a crucial issue in education.

An ideal language policy should recognize linguistic and cultural diversity in a country and allow diversity to play a role in development, especially with regards to education, administration, and so on (Batibo 2014, 18).

Furthermore, opportunity, equity and identity influence policy development. This includes, opportunity which implies giving citizens the chance or prospect for advancement or success (Kioko 2014, 24). A language policy which is in harmony with equity tackles the avoidable factors that fuel inequalities (Kioko 2014, 26).

Some hybrid assessment (Barrett 2014, 74), which assesses integrated content and language is ideal in the ESS assessment context. Working towards social justice requires attention to a range assessments (Barrett 2014, 75).

It is against this background that factoring in a project module can bring in some radical change in ESS assessment (cf. Gibbs 1999). Project assessment is meant to inform students about how to do better and create feedback about their learning achievements. A project is thus a great contributor to student learning (cf. Knight 2001).

\section{ESP GROUP PROJECT MODULE}

The ESP project module consists mainly of outcomes, credit value, assumption of prior learning, resources and teaching approach.

\section{Outcomes}

Assessment criteria are statements of achievement and need to be developed alongside the development of the curriculum and syllabus. They influence both the materials and the assessments (De Chazal 2014, 302).

The module outcomes can be divided into critical cross-field outcomes and specific intended outcomes.

\section{Critical cross-field outcomes}

Students should be able to identify and solve problems, work in a team, organize and manage themselves, collect, analyse and evaluate information, communicate effectively, use science and technology, recognize problem solving contexts, reflect on and explore effective learning 
strategies, participate as responsible citizen and explore education and career opportunities.

\section{Specific intended outcomes}

Specific intended outcomes imply that students should be able to investigate a problematic issue such as ‘Communicable Diseases’ and 'Global Warming', use reference sources, paraphrase information, refer in-text appropriately, use power point for an oral presentation, make an oral presentation, write a project report and write a bibliography.

\section{Module units}

The ESS project module consists of the following units: searching for information in the library, in-text referencing, making an oral presentation, writing a bibliography and writing a project report.

\section{Credit value}

Learners' needs and characteristics ought to determine the purpose and the credit value of a module. Moreover, the module designer needs to consider the learning assumed to be in place.

BSc EDP sticks to teaching 170 students on average, in five groups of about 30 students in each of the five core subjects. The classes are small but are also labour-intensive as the lecturers in ESS would on average spend 5 contact sessions per week with each of the 5 groups (cf. Jansen, Ntshingila-Khosa and Cranfield 2005; Ngoepe 2007).

The project module is earmarked for the last term and is usually the last module to be taught. Groups start working on their projects about 2 weeks before the winter recess. Despite the out-of-class time that project groups are expected to spend working on the project prior to presentations, the BSc EDP suspends teaching and learning activities for one week for the culmination of the project activities. This culmination is condensed into one week which translates into 35 hours (7 hours x 5 days), excluding the out-of-class time students spent.

\section{Assumption of prior learning}

It is assumed that ESS teaching staff members are part of the BSc EDP staff. These staff members are also members of their mainstream subject departments and working groups were established in all subject disciplines to carry out the process of curriculum development. Senior members of mainstream staff act as external examiners for the UNIFY examination and examination results are submitted to the Dean's Office. This illustrates the close involvement of mainstream academics in this science access programme (Cantrell 1993; Kahn and Volmink 
1994).

It is also assumed that students have studied English for General Purposes (EGP) up to National Senior Certificate (NSC) level. In addition, students shall have been taught how to use language structures and features in a science context during the first three terms of their academic year.

\section{Resources}

Resources include prescribed textbooks, ESS course manuals, ESS reference materials, periodicals and websites.

Texts and tasks are at the heart of an ESP syllabus (De Chazal 2014, 53). Texts tend to be situated in a particular context for clearly defined readers or listeners and for a particular purpose (De Chazal 2014, 57).

\section{Textbooks}

Prescribed textbooks are 'The Unity and Diversity of Life' by Starr and Taggart for Biology, ‘The World of Physics' by Avison and 'Matter and its Changes' by Brady and Senese for Chemistry.

\section{ESS course manuals}

ESS Course manuals are 'ESS Grammar and Word Classes Module’, 'ESS Writing Module 1', 'ESS Writing Module 2' and 'Readings in Science Comprehension Book'.

\section{Reference materials}

Reference materials include the following: 'Longman Dictionary of Contemporary English' New Edition, 'Dictionary of Science’ New Edition, 'Thesaurus in Clear A - Z Form', 'Practical English Usage: International Students’ Edition by M. Swan, 'Computer Literacy Manual', periodicals such as 'New Scientist' and 'Mail and Guardian', and websites such as 'Google', 'Yahoo', 'Mamma’ and 'Wikipedia'.

Furthermore, digital tools can offer ways to support the teaching and learning of traditional language and skills, including those needed for academic study. To enhance learning, technologies are best seen as resources rather than objects (De Chazal 2014, 319).

Digital resources also include 'grey literature' which means any digital or print publication which is not controlled by commercial publishing (http://www.greynet.org). Grey literature includes many important types of documents such as government reports and it has always been 
available in the pre-digital era even though it was a problem for researchers and librarians because it was difficult to access and trace (De Chazal 2014, 322).

\section{Teaching approach}

The ESP project instructional method and materials for the BSc EDP team of lecturers are meant to encourage students’ meaningful connections across Biology, Chemistry, English, Mathematics and Physics subject areas (cf. Kincheloe, Mclaren and Steinberg 2011).

Although most direct teaching remains face to face through lectures, seminars and tutorials, nowadays teaching and learning is increasingly supported, supplemented and complemented through the use of technologies (De Chazal 2014, 320). ESS students are also encouraged to use technologies.

Regulative and instructional registers operate in any classroom. Therefore, when lecturers give instructions for activities, explain classroom procedures or maintain order, they are creating and maintaining the conditions in which subject related knowledge and skills can be learned. Thus, proper conditions for productive classroom activity need to be set up and maintained mainly by the lecturer (Llinares, Morton and Whittaker 2012, 29).

It is against this background that the ESP project module approach is subsumed under choice of topic, project groups, searching for information, referencing, written and oral reports and assessment.

\section{Choice of topic}

The ESS lecturer decides on a topical theme which students should research. Then, the lecturer comes up with ten or more topics emanating from the chosen theme. Next, the lecturer divides students into groups of about ten or more for the project. Each group tosses for a topic it has to research.

\section{Project groups}

Groups then decide on the venue and time for their first as well as subsequent meetings. Group members share responsibilities by deciding on a project group leader, the scribe for their meetings, time-keeper, and so on. Group members brainstorm on what they need in order to investigate their selected topic.

\section{Searching for information}

The lecturer demonstrates how to search for information in the library as well as in different 
websites. Next, students search for relevant articles on 'Climate Change' or 'Green Energy', for example, based on a topic they shall have selected. They are advised to bring their articles to the subsequent meeting.

\section{Referencing}

The lecturer demonstrates paraphrasing, plagiarism and in-text referencing. Lastly, students are given 3 passages from 3 sources to paraphrase, and acknowledge the sources used.

The lecturer demonstrates how to write a bibliography. Next, students write a bibliography on the 3 paraphrased passages. Then, individuals search for relevant information; 2 articles or sources per member are expected; some are recommended and those without biographical details are rejected.

The lecturer checks articles and bibliographic details students have brought. Students circulate articles among group members in order to avoid repetition. Relevant articles are accepted while irrelevant ones are rejected.

\section{Written and oral reports}

The structure of a project written report is discussed in class. Each group agrees on a proposed structure; lecturer assesses the draft structures and gives feedback. Then, members take part in the writing task by sharing aspects or subheadings to be included in the report. Next, students agree on the sequence of ideas and write a draft report.

A computer literacy lecturer in the BSc EDP programme demonstrates power point usage in the computer laboratory. Then, students perform a task on power point during computer literacy contact session.

Editing is modelled to the whole group by the lecturer. Group members edit their drafts. The lecturer edits group draft reports and gives feedback. Students do corrections and draft oral reports on power-point on the basis of their written reports. The lecturer edits the draft oral reports and gives feedback. Student groups refine their oral reports.

\section{Assessment}

The students rehearse their oral reports in their groups. They then present to an audience comprising ESS lecturers, content lecturers and students. They are assessed by ESS - as well as content lecturers, and get some feedback.

Lastly, students refine their written reports and submit for assessment. The ESS lecturer marks the reports and gives corrective feedback. The underlying logic of such an approach is 
that if students, language and content lecturers assess the group project together, underprepared science students stand to benefit more.

\section{METHODOLOGY}

This research is ethnographic in design. Ethnography can be interpretive and involves gathering naturally occurring data from numerous sources (Hyland 2006, 65). Students, language - and contract lecturers assess the ESS group project in concert. Ethnography also provides an account grounded in the data collected which develops a conceptual explanatory framework ((Hyland 2006, 66). Thus, a variety of data collection methods can lend themselves to ethnography if applied with the objective of understanding the distinctions that are meaningful to the members of a given community ((Hyland 2006, 67). The researcher interprets data gathered from oral and written presentations, as well as ESS tests (see Results). Above all, Richards, Ross and Seedhouse (2012, 35) assert that ethnography is an empirical activity, depending for its success on extensive and detailed recording of the things happening in a setting (see Teaching Approach).

The distinguishing feature of the design is that the results of the secondary data type are meaningful only in the context of the other data set (Richards, Ross and Seedhouse 2012, 308). This implies that assessment of the ESP group project is secondary to ESS criterion-referenced tests. The exact focus of the research will evolve contextually and emerge in its original location only after some fieldwork has been done (Dornyei 2007, 131). Traditionally, students sat for 4 written tests. Thus, project assessment replaces the $4^{\text {th }}$ ESS test.

\section{RESULTS}

Results are presented in a graph in Figure 1.

Test average marks for the period 2007 to 2010 are 54.6, 59.2, 59.6 and 59 respectively while project averages for the same period are 63.6, 68, 58.7 and 65 respectively.

Overall results for this period indicate that although science students pass in both assessment types, they perform better in projects than in ESS ESP tests, except in the year 2009. Written tests average marks in the period under review are 58 whereas average projects marks for the same period are 63.9.

\section{DISCUSSION}

The ESS course is meant to improve the proficiency levels of first entering UL students who are at risk of not making it in the UL science Faculties. Students have to pass Mathematics and ESS to qualify for a pass in the programme. 


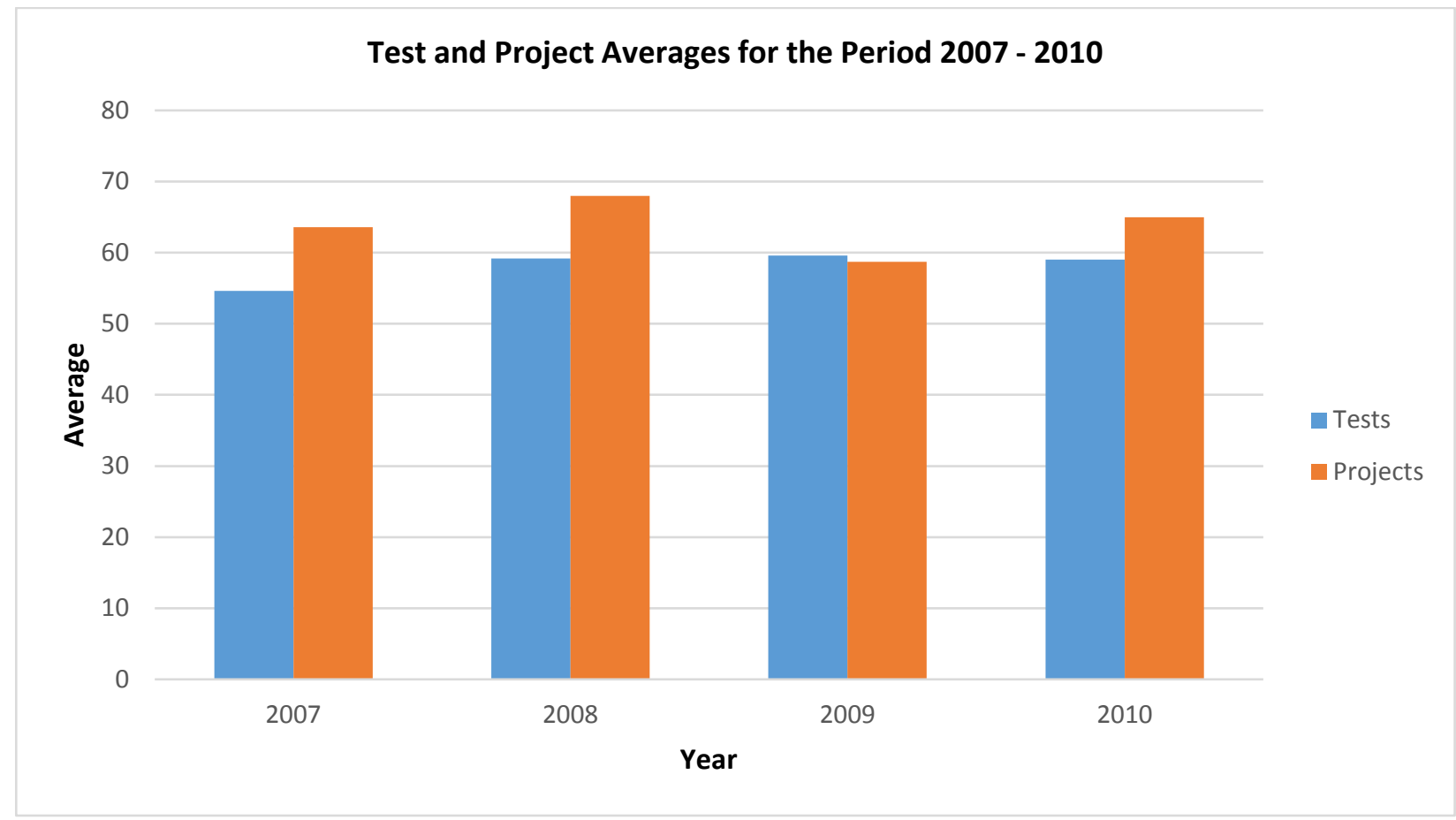

Figure 1: Comparison of Test and Project Average Marks

Cohorts of underprepared students are admitted into the BSc EDP programme annually. They are then randomly divided into smaller groups of 30 on average, to ensure and sustain the necessary individual attention accorded to the students, in line with the ethos of the BSc EDP programme for underprepared science students. However, ESP project groups are structured differently from the BSc EDP main groupings.

The ESS course is premised on some of the following tenets: pre-determined English proficiency levels of cohorts of students, a learner-centred approach, an integrated science curriculum, regular class attendance, a conducive teaching and learning environment, programme groups which are allotted equal teaching time, exposing students to team teaching, highly motivated students, internal and external assessment and high staff morale.

The year 2009 proved to be unique in that ESP group project students performed slightly better in tests than in projects (see Results). This trend could be attributed to the atypical BSc EDP teaching and learning environment that prevailed for both staff and students. The situation could have been inadvertently affected by low staff morale due to eminent staff restructuring. Eventually teaching staff was redeployed to UL cognate departments. This unusual performance of students demonstrates how sensitive and delicate students at risk of not making it can be. 


\section{CONCLUSION AND RECOMMENDATIONS}

When language and content lecturers assess a science ESP project in concert, under-prepared students tend to perform better. It is implicit that the lecturers' multidisciplinary strengths in Biology, Chemistry, Computer Literacy, English, Mathematics and Physics support students in executing the group project.

Moreover, formal groups foster interaction among students, language - and content lecturers as they ideally generate knowledge while students learn from one another in their respective project groups.

The multidisciplinary nature of this group project assessment venture, comprising a number of tasks, enriches the ESP assessment. Thus, ESP project assessment forges team work among students, language - and content lecturers for the benefit of under-prepared science students.

This triangular multidisciplinary assessment of the ESP module integrates language and science content by tapping on the lecturers' skills and on the potential of students in the BSc EDP.

Both groups of lecturers, that is the language as well as the content ones, feature as facilitators and consultants in an ESP learning situation. Thus, inadvertently, there is agency among groups of students to take charge of their learning.

That project results can be better interpreted in relation to traditional ESS written tests augers well for the use of different assessment methods in ESP teaching and learning.

Although ESP project implementation is labour-intensive and time-consuming, this quintessentially South African approach does pay dividends in that it boosts the performance of the students in BSc EDP. Therefore, the attrition rate of first entering underprepared science students enrolling at universities can be increased in the long term.

Since ESP group project work complements ESS traditional written tests, the inclusion of an ESP project as an additional form of assessment in the science foundation curriculum is essential and even seminal. This inclusion serves as another form of scaffolded formative assessment which can add value to ESP assessment practices.

Individual rather than group project work could benefit underprepared science students more. That could also call for more time dedicated to project work and more lecturers participating, in future.

It remains phenomenal to let content lecturers in collaboration with ESP lecturers choose themes and decide on topics emanating from the themes to be researched by ESP project students. 
Some post-project questionnaire or interview of the stakeholders participating in the assessment could help monitor the impact of the project on the BSc programme. This experience could also be used to assure the quality of the ESP group project; the input of students in this regard could also be valuable.

\section{REFERENCES}

Alidou, H. and C. Glanz. 2014. A frame of reference on quality youth and adult literacy in multilingual contexts. In Language rich Africa: Policy dialogue. The Cape Town language and development conference: Looking beyond 2015, ed. H. Mcllwarith. London: British Council.

Barrett, A. M. 2014. Measuring literacy post-2015: Some social justice issues. In Language rich Africa: Policy dialogue. The Cape Town language and development conference: Looking beyond 2015, ed. H. Mcllwarith. London: British Council.

Batibo, H. M. 2014. Searching for optimal national language policy for sustainable development. In Language rich Africa: Policy dialogue. The Cape Town language and development conference: Looking beyond 2015, ed. H. Mcllwarith. London: British Council.

Bloch, C. 2014. Growing young readers and writers: underpinnings of the Nal'ibali National readingfor-enjoyment campaign. In Language rich Africa: Policy dialogue. The Cape Town language and development conference: Looking beyond 2015, ed. H. Mcllwarith. London: British Council.

Cantrell, M. 1993. The Inception Report of the UNIFY Project. Unpublished Document. Sovenga: University of the North.

Davidson, M. 2014. Foreword. In Language rich Africa: Policy dialogue. The Cape Town language and development conference: Looking beyond 2015, ed. H. Mcllwarith. London: British Council.

Department of Education. 1997. Towards a Policy Framework for Assessment in the general and further education and training phase in South Africa. Discussion Document. Unpublished Report. Pretoria: Department of Education.

De Chazal, E. 2014. English for academic purposes. Oxford: Oxford University Press.

Dornyei, Z. 2007. Research methods in applied linguistics. Oxford: Oxford University Press.

Dreyer, C. 2000. Assessment in outcomes-based education: A guide for teachers. Journal for Language Teaching 34(3): 266-284.

Ellis, R. 2003. Task-based language learning and teaching. Oxford: Oxford University Press.

Fouche, I. 2007. The influence of tutorials on the improvement of tertiary students' academic literacy. Per Linguam 23(1): 45-55.

Genesee, F. and J. A. Upshur. 1996. Classroom-based evaluation in the Second Language education. Cambridge: Cambridge University Press.

Gibbs, G. 1999. Using assessment strategically to change the way students learn. In Assessment matters in higher education: Choosing and using diverse approaches, ed. S. Brown and A. Glasner. Buckingham: SRHE and Open University Press.

Glasman-Deal, H. 2010. Science research writing for non-native speakers of English. London: Imperial College Press.

Hibbard, K. M. 1996. A teacher's guide to performance-based learning and assessment. Alexandria, VA: Association for Supervision and Curriculum Development.

Hyland, K. 2006. English for academic purposes: An advanced resource book. London: Routledge

Jansen, J., R. Ntshingila-Khosa and C. Cranfield. 2005. University of the North Mathematics and Science Foundation Year (UNIFY) Phase II. Final (Ex-post) evaluation. Unpublished report. Pretoria: European Union Commission. 
Johnson, D., R. T. Johnson and E. J. Holubec. 1998. Cooperation in the classroom. Boston: Allyn and Bacon.

Kahn, M. and J. Volmink. 1994. Evaluation of the University of the North Foundation Year. Unpublished Report. Pretoria: European Union Commission.

Kincheloe, J. L., P. Mclaren and S. R. Steinberg. 2011. Critical pedagogy and qualitative research: Moving to the bricolage. In The SAGE handbook of qualitative research, ed. N. M Denzin and Y. S. Lincoln. London: SAGE Publications Inc.

Kioko, A. N. 2014. Development of national language policies in East Africa: The interplay of opportunity, equity and identity. In Language rich Africa: Policy dialogue. The Cape Town language and development conference: Looking beyond 2015, ed. H. Mcllwarith. London: British Council.

Knight, P. 2001. A briefing on key concepts - Formative and summative, criterion and norm-referenced assessment. LTSN Generic Centre.

Lebrun, J. 2010. When scientists present. Singapore: World Scientific.

Llinares, A., T. Morton and R. Whittaker. 2012. The roles of language in CLIL. Cambridge: Cambridge University Press.

Longman Dictionary of Contemporary English. 1995. Longman Group Ltd.

Mackey, A. 2012. Input, interaction and corrective feedback in L2 learning. Oxford: Oxford University Press.

Masters, G. and M. Foster. 1996. Developmental assessment: Assessment resource kit. Melbourne: The Australian Council for Educational Research Ltd.

McMahon, P. 2013. Group work: Work together for academic success. London: Harper Collins.

Ngoepe, L. J. 2007. The University of Limpopo Mathematics and Science Foundation Year Course in English and Study Skills: An evaluation. Potchefstroom: North West University. Thesis - PhD.

Ngoepe, L. J. 2012. To what extent do science ESP learning materials fit the purpose for which they have been devised? An evaluation in terms of Cronje's (1993) criteria. SAALT Journal for Language Teaching 46(1): 60-73.

Richards, K., S. Ross and P. Seedhouse. 2012. Research methods for Applied Language studies. London: Routledge.

Robinson, P. 1991. ESP today. Hemel Hempstead: Prentice Hall International.

Rogier, D. 2011. Assessment practices and beliefs: strengthening assessment literacy in EFL teachers. In IATEFL 2010 Harrogate Conference Selections, ed. T. Pattison. Canterbury: University of Kent

Salvia, J. and J. E. Yssedyke. 1995. Assessment. Boston: Houghton Mifflin Company.

Verhoeven, P. and N. Verloop. 2002. Identifying changes in teaching practice: Innovative curricular objectives in classical languages and the taught curriculum. Journal of Curriculum Studies 34(1): 91-102.

Zaaiman, H. 1998. Selecting students for Mathematics and Science. Pretoria: HSRC. 


\section{APPENDICES}

Appendices comprise students' assessment sheet, content and language staff assessment sheet for oral presentations, an ESS staff marking scheme for written reports, and sample ESS Test 4.

\section{A. Students' Editing Grid for Draft Reports}

\begin{tabular}{|l|c|}
\hline \multicolumn{1}{|c|}{ Item } & Abbreviation \\
\hline Wrong Word Class & WWC \\
\hline Incomplete Sentence & WS \\
\hline Wrong Spelling & S/P \\
\hline Singular/Plural Mistake & $\mathrm{PI}$ \\
\hline Paragraph arranged per idea & SI \\
\hline Structure Incomplete (no title, introduction, body or conclusion) & ID \\
\hline Irrelevant Discussion (of topic) & \\
\hline
\end{tabular}

NB: Underline the error and write the relevant abbreviation above it.

\section{B. Content \& Language Lecturers' Assessment Sheet for Oral Presentations}

\section{Date \\ Group No. \\ Topic \\ Total Score}

\begin{tabular}{|l|c|c|}
\hline \multicolumn{1}{|c|}{ Presentation } & Possible Score & Actual Score \\
\hline Structure & 5 & \\
\hline Language \& Content (in key words) & 15 & \\
\hline Supporting material (tables, graphs, pictures, etc.) & 3 & \\
\hline Cohesion & 5 & \\
\hline Deportment (gestures, eye contact, use of voice, etc.) & 2 & \\
\hline Total & $\mathbf{3 0}$ & \\
\hline
\end{tabular}

Comments:

\section{ESS Staff Marking Guide for a Written Report}

\section{Band Scale}

23-30: A coherent report; few mechanical errors; varied sentence patterns; some attempt to use cohesive devices and make the text sound interesting.

16-22: On the whole mechanically accurate; not much attempt to use cohesive devices or add interest to the text; sentence patterns repetitive and pedestrian.

7-15: Answers riddled with errors - grammar, spellings, omission of articles, misuse of comparatives etc. Too short answers will fall into this band.

0-6: The report is practically incomprehensible. 


\section{Sample ESS Test 4}

BSc EDP

ESS Test 4

\begin{tabular}{ll}
\hline Date: & 01 October 2007 \\
Duration: & 1 Hour \\
Marks: 20 & \\
Surname \& Initials:
\end{tabular}

Student No.

Instruction(s):

Expand the following notes into paragraphs which will collectively comprise a passage.

1. General

\section{Aluminium}

(a) $7.5 \%$ of earth's crust - commonest metal

(b) 1 of 6 most widely used mets. in the world

\section{Properties}

\section{A. Density}

(a) Very low density (light)

(b) used for bodywork of aircrafts, cars etc.

\section{B. Corrosion resistance}
(a) Resistant to deep oxidation
(b) Outer surface, easily converted to Al O (Aluminium Oxide)
(c) $\mathrm{Al} \mathrm{O}$ protects $\mathrm{Al}$ from $\mathrm{HO}$ and $\mathrm{O}$
(d) Suitable for window frames, exterior doors, etc.

\section{Conductivity}
(a) Not so good as $\mathrm{Cu}$, but less dense
(b) Therefore better than $\mathrm{Cu}$ when considering weight
(c) Used for electricity distr. in Britain
(d) Conducts heat well; used for cooking pots, etc.
D. Other Advantages
(a) Cheap
(b) Attractive
(c) Doesn't need painting

\section{Aluminium Alloys}

(a) $\mathrm{Cu}, \mathrm{Mg}$, Si make Al stronger e.g. duralumin

(b) Duralumin gets stronger \& harder 4-5 days after making (age-hardening)

(c) duralumin is easy to work \& shape after manufacturing but strong later 